\title{
Análise de gênero para o adoecer de câncer
}

\author{
Gender analysis in acQuiring cancer
}

Analisis de género a la adQuisición de cáncer

\section{Antonia Tayana Franca Xavier', Márcia Barroso Camilo Ataíde", Francisco Gilberto Fernandes Pereira", Velma Dias Nascimento"}

'Universidade de São Paulo. Escola de Enfermagem de Ribeirão Preto. Departamento de Enfermagem Geral. Ribeirão Preto, SP "Universidade de Fortaleza. Fortaleza, CE

Submissão: 29/07/2009

Aprovação: 17/10/2010

\section{RESUMO}

O objetivo deste estudo foi compreender o processo do adoecimento de câncer, em homens e mulheres, na perspectiva do gênero. Participaram como informantes Quatro mulheres e três homens, portadores de câncer de cólon e reto Que estavam em tratamento ambulatorial, numa Instituição de Saúde Privada, no município de Fortaleza-CE, no mês de julho de 2008. As informações foram coletadas por entrevista semi-estruturada sendo organizadas em categorias conforme análise de conteúdo e analisadas consoante estudiosos da temática de gênero. As categorias Que emergiram foram: $O$ adoecimento de câncer: fragmentações e limitações na vida; uma vida em transformação: das ameaças às superações. Os depoimentos elucidam todo o processo de adoecimento de câncer e a percepção de gênero sobre este evento além de revelar Que os estereótipos criados pela sociedade acerca de gênero também se traduzem no comportamento apresentado pelas pessoas Que adoecem de câncer.

Descritores: Identidade de Gênero; Neoplasia; Comportamento.

ABSTRACT
The objective of this study was to understand the process of the sicked of cancer, in men and women, the perspective of the gender. To four women and three men, carriers of cancer of cólon and rectum who were in ambulatorial treatment, in an Institution of Private Health, the city of Fortaleza-CE, in the month of July of 2008 had participated as informing. The information had been collected by halfstructuralized interview being organized in categories in agreement analysis of studious content and analyzed consonant of the thematic one of gender. The categories that had emerged had been: The sicked of cancer: spallings and limitations in the life; a life in transformation: of the threats to the overcomings. The depositions all elucidate the process of sicked of cancer and the perception of gender on this event beyond disclosing that the stereotype created by the society concerning sort also are expressed the behavior presented for the people who sicked of cancer.

Key words: Gender Identity; Neoplasms; Behavior.

\section{RESUMEN}

El objetivo del estudio ha sido entender el proceso del enfermar de cáncer, en hombres y mujeres, la perspectiva del género. Informaran cuatro mujeres y a tres hombres, los portadores del cáncer del colon y el recto Que estaban en el tratamiento clínico, en una institución de la salud privada, la ciudad del Fortaleza-CE, en el mes de julio de 2008. La información había sido recogida por la entrevista estructurada Qué organizada en categorías en análisis del acuerdo del contenido estudioso y de la consonante analizada de el temático del género. Las categorías Que habían emergido habían sido: Enfermar de cáncer: fragmentación y limitaciones en la vida; una vida en la transformación: de las amenazas para los superación. Las deposiciones todas aclaran el proceso de enfermar de cáncer y de la opinión del género en este acontecimiento más allá de divulgar Que el estereotipo creado por la sociedad referente a clase también está expresado el comportamiento presentado para la gente Que enferman de cáncer.

Descriptores: Identidad de género; Neoplasias; Conducta.

AUTOR CORRESPONDENTE Antonia Tayana Franca Xavier. Rua Comandante Marcondes Salgado, 1058, apto. 84. CEP I 4010 - 150.

Ribeirão Preto, SP. E-mail: tayanaxavier@uol.com.br 


\section{INTRODUÇÃO}

Uma das enfermidades de elevada incidência, atualmente, são as neoplasias, as Quais ocorrem devido transformações celulares mutacionais Que comprometem de forma crônica tecidos, órgãos ou, na maioria das vezes, o sistema orgânico por completo. Geram efeitos biológicos, mas também, grandes repercussões psicológicas, por serem estigmatizantes e embutidas de significados sociais de preconceito e, de por vezes de reclusão.

Uma análise da estimativa de câncer publicada pelo INCA ${ }^{(1)}$ no Brasil revela Que os tumores mais incidentes para mulheres serão os de mama com risco estimado de 49 casos a cada cem mil mulheres, enquanto que para os homens, serão os de próstata, com risco estimando de 54 casos para cada cem mil homens. Quando associados ambos os sexos, o segundo tipo de câncer mais incidente será o de cólon e reto, com cerca de 14 casos para homens e 15 para mulheres, considerando a proporção para cada cem mil habitantes.

O câncer de cólon e reto pode gerar distúrbios na imagem corporal de seus acometidos, uma vez Que sejam submetidos à ostomia intestinal - via artificial externa de eliminação de fezesQue propicia desconforto social e muitas vezes diminuição na autoestima de homens e mulheres. Associado a isto ocorre mudanças radicais no padrão alimentar, configurando, portanto um novo estilo de vida e readaptação com o funcionamento do corpo e dos hábitos de vida.

As interpretações Que homens e mulheres, portadoras de câncer de cólon e reto, têm sobre si e seu estado de saúde, bem como a forma Que vivenciam o adoecimento tem aguçado nosso interesse desde os primeiros contatos com essa clientela em campos de práticas das atividades extracurriculares de enfermagem em clinica médica. Esta aproximação permitiu-nos constatar Que homens e mulheres demonstravam comportamentos diferentes Quanto ao modo de lidar com a nova condição, Quer seja nos cuidados com a saúde física, Quer seja na adaptação psicológica.

Sabemos Que o olhar lançado para si, para os outros e para as situações do mundo vivido, é aprendido na sociedade a partir das regras e responsabilidades estabelecidas para homens e para mulheres, nos diferentes contextos culturais, podendo ser modificado com o tempo.

Isto nos remete às nuances de gênero, Que vislumbra a organização social da diferença sexual, não implementando diferenças físicas fixas e naturais entre homens e mulheres, mas fazendo existir significados para as diferenças corporais, os Quais variam de acordo com as culturas, os grupos sociais e o tempo ${ }^{(2-3)}$.

O entendimento de que gênero é algo que vai se construindo e Que é um produto histórico, torna-se imprescindível para compreender determinados comportamentos, Que são invariavelmente mutáveis. No tocante à saúde, homens e mulheres a percebem de formas diferentes, o Que gera grande impacto nas estratégias Que utilizam para cuidarem de si mesmos, e no manejo Que conduzem suas situações de desordens físicas e psicológicas ${ }^{(4)}$.

Porventura, os estereótipos de modelos comportamentais impostos pela sociedade ditam o modo como os homens e as mulheres devem cuidar de si e devem reagir no momento do confronto com diagnóstico de câncer?

Alguns pesQuisadores têm se aproximado dessa temática na perspectiva de gênero, haja vista Que a produção acadêmica sobre gênero e saúde no Brasil circunscreve à grande área de saúde, tendo a enfermagem como uma das áreas Que mais produz conhecimento neste setor de pesquisa ${ }^{(5)}$.

Sugere-se que os profissionais de saúde fieuem atentos às relações de gênero Que perpassam as experiências das pessoas, Quer em estado de saúde ou doença. Nessas relações, os homens e as mulheres vivem problemas comuns, como é o exemplo do desconforto e, em alguns casos, são estigmatizados devido as suas aparências físicas causadas pela doença. Mas por outro lado, no relacionamento estabelecido entre homens e mulheres, convive-se com a diferença ${ }^{(6)}$.

O processo saúde-doença é uma construção social, e Que as relações Que os indivíduos estabelecem inter e intragêneros colaboram com as práticas por eles utilizadas no manejo dos infortúnios, até porque esta dinâmica parece estar ligada ao gênero porque na nossa sociedade dita-se Que os homens são mais objetivos, racionais, enQuanto Que as mulheres são mais vulneráveis, sensíveis a determinadas situações ${ }^{(7)}$.

Uma outra dimensão na explicação de diferenças na saúde entre homens e mulheres refere-se aos aspectos psicológicos associados à forma como as pessoas percebem os sintomas, avaliam a gravidade da doença e decidem o Que fazer com respeito à sua saúde, como foi abordado por autores ${ }^{(8)}$ ao dissertar sobre as representações de gênero e corpo de pessoas acometidas de alguma morbidade.

Entendemos Que os estudos com abordagem de gênero são importantes no campo da enfermagem porQue as mudanças sociais ao longo das décadas, e o perfil emergente de patologias de curso crônico, como o câncer, abrem uma lacuna no ambiente científico sobre a forma como homens/masculino e mulheres/feminino lidam com sua saúde, tornando-se relevante, responder a inфuietação sobrescrita:

Como os homens e as mulheres enfrentam o adoecer de câncer?

Entendemos Que saber captar as diferenças Que são socialmente construídas entre os papéis masculino e feminino é de fundamental importância para a promoção de ações educativas e de cuidado no campo da saúde. Focalizar este tema com abordagem de gênero é uma forma relevante de ampliar a base de conhecimentos teóricos relativos ao objeto de estudo, por isso, o nosso objetivo é compreender o processo do adoecimento de câncer, em homens e mulheres, na perspectiva do gênero.

\section{METODOLOGIA}

Tratou-se de um estudo do tipo descritivo, a Qual permite observar as características de determinados sujeitos, suas opiniões, atitudes e $\operatorname{crenças~}^{(9)}$. A abordagem selecionada foi a Qualitativa, a Qual é enaltecida como a Que se baseia na premissa de Que os conhecimentos sobre os indivíduos só são possíveis com a descrição da experiência humana, tal como ela é vivida e tal como ela é definida por seus próprios atores ${ }^{(10)}$.

O local do estudo foi em uma Instituição privada de tratamento oncológico clínico, situada em Fortaleza-CE, Que tem como objetivo oferecer a modalidade terapêutica de Quimioterapia anti-neoplásica ambulatorial e com internação, assistindo ao paciente desde a fase diagnóstica, perpassando pelo tratamento, e por fim, na alta por cura ou prestação de cuidados paliativos. A equipe multiprofissional 
é composta de médicos oncologistas, enfermeira especialista em oncologia, farmacêutica, psicóloga, nutricionista e técnicos de enfermagem.

Os participantes foram três homens e Quatro mulheres, portadores de câncer de cólon e de reto e Que estavam em acompanhamento ambulatorial, na referida instituição de saúde, independente do tempo de diagnóstico, da faixa etária, da condição social, da escolaridade.

O número de participantes do estudo foi determinado pelo critério da saturação e Qualidade das informações, adotado em pesquisas eualitativas, onde a coleta de dados finaliza com a identificação de convergências e divergências dos depoimentos, não sendo a preocupação maior a Quantidade e sim a Qualidade ${ }^{(1)}$.

A fim de resguardar a identidade dos pacientes foram-lhes atribuídas nomes de deuses gregos os Quais simbolizam a personificação dos sentimentos Que mais foram expressos durante a entrevista.

Durante o mês de julho de 2008, utilizou-se para coletar as informações a entrevista semi-estruturada, contendo as seguintes Questões norteadoras: 1) Como é para você ser um(a) homem (mulher) portador de câncer?; e 2) Como você percebe sua vida diária desde o surgimento do câncer até os dias atuais? Para nos assegurarmos da ampla captação das informações dos depoentes, utilizamos o gravador como recurso complementar.

Para a elucidação dos aspectos de gênero contidas nas falas dos homens e das mulheres, estas foram confrontadas, procurandose apreender os pontos relevantes Que permitiram contextualizar o igual e o desigual dos indivíduos com câncer de cólon e reto, e, posteriormente, essas falas foram ancoradas no referencial de gênero, considerando a perspectiva relacional ${ }^{(12)}$.

Para tanto, recorremos ao Método de Análise de Conteúdo proposta por Bardin ${ }^{(13)}$, Que propõe as seguintes fases de análise temática: I ${ }^{a}$ FASE) Pré-análise - organização propriamente dita, leitura e escolha dos documentos a serem analisados, para retomada das hipóteses e dos objetivos iniciais com posterior reformulação do material coletado, elaborando, assim, os indicadores Que orientem a interpretação final; 2a FASE) Exploração do material consistiu na operação de codificações, onde os dados brutos foram tratados com o objetivo de compreender o texto onde foram classificados e agregados em categorias e subcategorias, significativas e válidas, sob um tema Que os identificasse; $3^{\text {a }}$ FASE) Tratamento dos resultados, a inferência e a interpretação - nesta fase, os autores procuraram analisar os significados das falas dos homens e mulheres, interpretando e entendendo o enfoque das informações obtidas e as suas percepções sobre a doença na perspectiva de gênero.

Emergiram as seguintes categorias e subcategorias: 1) $\mathrm{O}$ adoecimento de câncer: fragmentações e limitações na vida I - I) o adoecer de câncer: fragmentação de uma vida; 1-2) Limitações do viver impostas pelo tratamento; 2) Uma vida em transformação: das ameaças às superações; 2-1) A preocupação com a masculinidade; 2-2) A fragilidade e a fortaleza: ambigüidade feminina.

Esta pesquisa obedeceu a Resolução 196/96 do Conselho Nacional de Saúde ${ }^{(14)}$, envolvendo seres humanos e foi submetida e aprovada pelo Comitê de Ética em Pesquisa, da Universidade de Fortaleza - UNIFOR, logrando parecer favorável nº $179 / 08$.

\section{RESULTADOS E DISCUSSÃO}

\section{Categoria 1- Adoecimento de câncer: fragmentações e limitações da vida}

Os depoimentos demonstraram Que o processo do adoecimento veio acompanhado de interpretações próprias de homens e mulheres, estando envolvido nesse bojo o aspecto de gênero humano, Que influenciou no modo como se comportaram frente ao diagnóstico, ao conhecimento e ao tratamento do câncer.

Gênero deve ser entendido como a rede de traços de personalidade, atitudes, sentimentos, valores, condutas e atividade Que, através de um processo de construção social, diferencia os homens e mulheres ${ }^{(2)}$.

Partindo do princípio de gênero eneuanto rede de possibilidades de sentir e de expressão segundo o processo de construção social, é Que homens e mulheres, cada um ao seu modo, remeteram-se aos momentos vividos desde o diagnóstico até ao estágio de tratamento atual, como sendo um processo de fragmentação e de limitação dolorosa e carregada de obscuridade.

\section{Subcategoria 1.1- O adoecer de câncer: fragmentos de uma vida}

O período de transição entre a saúde e o adoecimento de câncer em mulheres e homens afetou não apenas suas próprias vidas, mas as de outras pessoas, levando-as a expressarem variados sentimentos e a adotarem comportamentos Que os ajudassem no enfrentamento do diagnóstico e na adaptação cotidiana ao tratamento requerido pela doença.

Essa transição é compartilhada por Kubler-Ross ${ }^{(15)}$ ao dizer Que a sabedoria de compartilhar uma notícia dolorosa com o paciente é uma arte, sendo necessário o reconhecimento dos mecanismos usados por muitos dos pacientes durante uma doença incurável e terminal, como o câncer. Esses mecanismos são descritos nos estágios de negação, raiva, barganha, depressão e aceitação. O existir do doente com câncer é marcado por um sofrimento contínuo, Que traduz sentimentos diferentes, dependendo dos momentos que vive e das crises Que experiencia ${ }^{(16)}$.

O primeiro estágio inicia com a negação, advindo com a surpresa e isolamento, caracterizado pela recusa de acreditar Que determinada informação seja verdadeira, podendo ser um estado temporário de choque do Qual se recuperará gradualmente. Vejamos os depoimentos que denotam esse estágio.

"Eu acredito Que o pior momento é Quando a gente ouve do médico Que está com um câncer. Sua cabeça dá um giro de num sei Quantos graus. Parece Que você morre e ressuscita em alguns minutos". (Afrodite)

"Desde que eu descobri que to com câncer acho que as coisas tão ficando cada vez mais difíceis. Eu num posso trabalhar, num posso passear, tenho vergonha de ficar perto das pessoas". (Hermes)

O depoimento de Afrodite sobre o momento do diagnóstico de câncer deixa transparecer ao mesmo tempo surpresa, isolamento e choque com o inesperado. Ao verbalizar que sua cabeça dá um giro de num sei Quantos graus, mostrou-se atordoada pelo enigma da doença e pelo sofrimento de vivenciar o limiar da vida e da 
morte como alguém Que morre e ressuscita em alguns minutos.

A mulher tem maior capacidade de adaptação a novas situações, pois ela, ao contrário do homem, se esforça na busca de conhecimentos sobre a doença e busca mais apoio social e emocional, além de orientar seus esforços cognitivos para lidar com as exigências e o estresse da situação $0^{(17)}$.

Ressalta-se com o depoimento de afrodite Que a revelação do diagnóstico de câncer é realmente um momento delicado e por vezes, crucial, pois a forma como o profissional de saúde dá a notícia interfere diretamente na relação do paciente com o seu próprio diagnóstico ${ }^{(18)}$.

Hermes revela Que com o diagnóstico surgiu uma barreira intransponível entre a vida cotidiana e a sua condição de saúde Que tanto a deixa angustiado pela transformação de sua vida Que esta cada vez mais difícil; assim, resta a Hermes afastar-se da convivência com os Quando diz ter vergonha de ficar perto das pessoas.

Acrescentando-se à experiência de vivenciar essas fases retrocitadas, o câncer provoca também uma extensão dos sintomas para além da dimensão física, provocando um fenômeno conhecido como dor total, o Qual é definido como um conceito no Qual se admite Que uma pessoa sofre não apenas pelos danos físicos Que possui, mas também pelas conseQuências emocionais, sociais e espirituais Que a proximidade da morte e a cronicidade pode lhe proporcionar $^{(19)}$. Veremos como o depoimento de Hera corrobora com essa premissa.

"Ter câncer causa dor de todo jeito, tanto espiritual, como física e moral. Parece que você se divide em duas, uma antes de ter o câncer e outra depois". (Hera)

Apesar de todo sofrimento causado pela doença a postura de Hera mostra a decisão de enfrentar o câncer, a começar pela constatação de Que não se pode ser a mesma. O sofrimento da contingência de ter câncer revela-se como um marco divisor produzindo mudanças nas maneiras específicas de viver.

Remetendo-se ao gênero enquanto rede de possibilidades é preciso ser outro homem, ser outra mulher, para viver num cotidiano de incertezas e ambigüidades de sentimentos Que surgem no enfrentamento das limitações impostas pela doença.

Subcategoria 1.2- Limitações do viver impostas pelo tratamento

A terapia do câncer, na Qual a Quimioterapia está associada, gera vários efeitos colaterais físicos, como náuseas, vômitos, anorexia, constipação, diarréia, fadiga e mucosite.

Estes efeitos evidenciam o status da doença a medida Que proporciona dor e sofrimento com os efeitos esperados. E Que, por conseguinte devido ao significativo impacto social, o acréscimo dos efeitos colaterais da Quimioterapia pode levar o paciente a sentir-se impotente para reagir e lutar pela sobrevivência ${ }^{(20)}$.

As conseqüências inevitáveis do tratamento Quimioterápico exacerbaram a preocupação e o sofrimento físico de Geia Quando verbalizou Que se sente mais cansada e mais debilitada.

"Só me sinto um pouco mais cansada, acho que é por causa da Quimioterapia, porque a gente fica meio debilitada". (Geia)

Não podemos nos esQuecer de Que esses homens e mulheres além de submeterem seus corpos a Quimioterapia também eram ostomizados, sendo isso mais um agravante ao tratamento, Que na maioria das vezes, gera distúrbios de auto-imagem além de ser um co-adjuvante para o retraimento social. Artemis denuncia de forma intensa esse aspecto Quando diz Que:

“(...) deixa a gente feia, careca, magra, por causa da Quimioterapia. Sem falar nessa bolsa de colostomia, eu tenho até vergonha de ter relações sexuais com meu esposo, e acho até que ele ta se afastando um pouQuinho de mim". (Ártemis)

Este depoimento deixa evidente Que a colostomia alterou a autoestima e provocou uma despersonalização em Artemis, influenciando de forma negativa no relacionamento conjugal ao ponto dela ter vergonha de manter relações sexuais e de nutrir sentimento de rejeição por parte do marido.

Chamamos a atenção para o fato de Que sendo Artemis uma mulher vaidosa as consequências desses sentimentos poderão contribuir para também alterar o relacionamento social, desenvolve seu estilo de vida comandado pelas respostas Que a terapêutica provoca, tendo como referencial a reação do outro para consigo.

Por outro lado é relatado Que alguns pacientes reagem conformando-se com a necessidade das ostomias, assumindo diante delas uma postura de otimismo, pois as vêem como um fator promotor de controle dos sintomas e sinais clínicos ${ }^{(20)}$. A experiência vivida com o ato de adoecer cria significados e se desenvolvem modos rotineiros de lidar com esta situação.

Em condições de enfermos passam a assumir atitudes com a adoção de estratégias e novas percepções sobre essa situação atual, como evidencia a fala posterior:

"Eu tenho a compreensão de Que a Quimioterapia é necessária, é uma coisa pra eu ficar boa, mas é uma fase muito complicada (...) mexe demais com a pessoa. Pior eu, Que já fiz duas colostomias e vivo com essas "danadas" penduradas no meu corpo, digo que são meus cachorrinhos de guia (risadas) já até me acostumei com elas, to virando expert no assunto". (Afrodite)

Sobre esta subcategoria, é interessante perceber Que foi ausente nos depoimentos masculinos a descrição de momentos dolorosos relacionados apenas ao tratamento. Os homens parecem encarar este momento com maior tranQüilidade apesar de não manifestarem esperança de cura tanto Quanto as mulheres.

Consoante a literatura ${ }^{(21)}$ e ratificado pelo nosso estudo está claro Que há diferenças no comportamento entre homens e mulheres principalmente no Que se refere aos aspectos psicológicos associados à forma como estes percebem os sintomas, avaliam a gravidade da doença e decidem Quanto ao tratamento. As mulheres declaram mais suas doenças, avaliam pior o seu estado de saúde, se submetem mais a exames e se apresentam mais vulneráveis ao surgimento de efeitos.

\section{Categoria 2- Uma vida em transformação: das ameaças as superações}

\section{Subcategoria 2.1 - A preocupação com a masculinidade}

Os homens mostraram Que vivem numa constante preocupação 
relativa às conseQüências do diagnóstico, especialmente sobre a debilidade física e da ameaça à sua masculinidade por viver um período de perda da autonomia e do controle total sobre si mesmo e as situações ao seu redor.

Um homem adoecer de QualQuer coisa já é difícil porQue parece Que a casa vai ficar sem chefe, imagine adoecer de câncer! (Zeus)

A gente às vezes se sente impotente (....) isso acaba afetando a masculinidade da gente, principalmente se a mulher do cara ouve um negócio desse. (Hermes)

Hermes e Zeus mostram toda a preocupação com a perda do Que consideram o poder masculino sendo Que esse tipo de reação é esperado, pois do gênero masculino não se espera sensibilidade, cuidado, fragilidade ou dependência ${ }^{(22)}$.

Nota-se Que esses depoimentos são repletos de alusões ao estereótipo de Que a masculinidade é ser um homem forte, produtivo, competitivo, ativo, envolvido nas tarefas múltiplas da vida cotidiana familiar e social, sendo um provedor exclusivo do lar. Entretanto esses homens com câncer viam-se como uma pessoa com fragilidades Que perderam o poder sobre o seu corpo em virtude de um tumor.

Hermes referenciava-se ao fato de Que após ter sido diagnosticado com câncer de reto, seus amigos o recriminavam e zombavam com brincadeiras Que denegriam a sua masculinidade, sugerindo Que o mesmo realizava práticas homossexuais devido a localização do câncer. Estes comentários o deixam atordoado porQue a imagem vinculada sobre masculinidade é aquela Que não está ligada a homossexualidade, e ligado a um ser forte e desafiador.

Ademais, foi identificado nas falas dos homens Que eles atribuem a origem do seu câncer a um fator potencialmente determinado por eles mesmos, os Quais são conhecidos como hábitos nocivos da masculinidade, tais como: tabagismo, álcool e má alimentação.

Ser homem e ter câncer (pausa...), eu acho Que isso é uma conseQuência de uma vida meio desmantelada na alimentação sabe? Nunca liguei muito pra esse negócio de prevenção, não me cuidava. (Apolo)

Com esta declaração de Apolo é possível perceber Que o homem da modernidade se vê como uma pessoa mais vulnerável, apesar de um poder socialmente atribuído ao masculino. Vê-se que ele reconhece Que o comportamento de falta de prevenção e de cuidado consigo mesmo gerou efeitos Que mudaram sua dinâmica de vida e depreciaram sua imagem de masculinidade ${ }^{(23)}$.

\section{Subcategoria 2.2- A fragilidade e a fortaleza: ambigüidade feminina}

As mulheres percebem o câncer como algo favorável a mudanças na sua maneira de viver, causando grande desordem emocional, uma vez Que as percepções femininas reproduzem uma imagem marcada por medo, sofrimento e dúvidas.

A pessoa com câncer pode trazer uma série de implicações em níveis: físico, emocional, afetivo, profissional, financeiro para o sujeito enfermo, bem como comprometer as relações familiares, gerando estresse, tensão e conflito ${ }^{(24)}$.

Podemos observar no depoimento de Ártemis Que o adoecer de câncer traz consigo uma sucessão de implicações emocionais e Que as experiências por ela vivenciadas é na verdade um grande complexo. A doença em si gera um grau de sofrimento enorme, uma vez Que amplia a fragilidade e a dependência de cuidados especiais que a doença exige, além da singularidade Que enfrenta diante da situação.

Porque a gente sendo mulher, o povo já vê a gente, assim, mais fraca, com menos força pra enfrentar os problemas (...). A gente fica muito bitolada, só pensa nisso direto, num vê a hora de ficar boa, porQue sei que curada num vou ficar mesmo. (Artemis)

Foi constatado Que o estudo de diferenças de gênero no enfrentamento pode contribuir de modo importante para a nossa compreensão dos processos cognitivos e dos fatores sociais e interpessoais Que afetam o desenvolvimento e o ajustamento do indivíduo ${ }^{(17)}$. Talvez a marca mais profunda causada pelo câncer seja a perda da identidade anterior e o medo da rejeição.

Percebemos ainda no depoimento de Afrodite Que ao comparar o câncer em homens e mulheres, a razão referida mostrou Que o enfrentamento da doença para o grupo feminino se torna mais difícil, pois demanda uma série de transformações a nível psicológico Quando diz Que:

“...Se eu fosse comparar o câncer pra um homem e uma mulher, acho Que pra mulher é mais complicado porque a gente tem um psicológico mais desenvolvido, chora por Qualquer coisinha, até com beijo de novela..." (Afrodite)

A partir do relato acima, podemos observar a vulnerabilidade feminina Que o estar com câncer suscita, a fragilidade da mulher em adoecer de câncer e isso gera grande estresse provocando alterações físicas e psicológicas nas suas vidas.

Em relação à forma como as pessoas percebem o seu estado de saúde, constatou-se que gênero é um fator de risco mais importante Que a idade ${ }^{(4)}$. Esses autores concluíram Que baixos níveis de saúde percebida estão associados ao gênero feminino.

Essas reações devem ser entendidas dando atenção e importância à história de vida de cada pessoa, considerando o contexto cultural e socioeconômico em Que ela está inserida, para isso é necessário reconhecer essa realidade e os limites de compreensão da situação existente de cada um. Nesse enfoque observamos que a grande diferença nas experiências vivenciada por essas mulheres está na complexidade sentida emocionalmente.

Os valores são o fundamento da diferença. As mulheres são diferentes dos homens, porque no centro de sua existência estão outros valores: a ênfase no relacionamento interpessoal, a atenção e o cuidado com o outro, a proteção da vida, a valorização da intimidade e do afetivo, a gratuidade das relações. A identidade feminina provém da interação com os outros. Daí serem as mulheres mais intuitivas, sensíveis e empáticas ${ }^{(25-26)}$.

\section{CONCLUSÕES}

As diferenças de gênero captadas nesta abordagem de câncer envolvem características tais como: perda da masculinidade, vulnerabilidade da vida, a reafirmação da mulher como um ser 
sensível e ao mesmo tempo forte mo processo de adoecer, a Quebra dos marcos de virilidade do homem, o preconceito vivenciado em ambos os gêneros e a necessidade de um suporte no enfrentamento da doença.

O momento do diagnóstico foi marcado por uma inevitável fragmentação na vida dos sujeitos, indistintamente para os gêneros. Foi percebido por meio das falas Que este foi o pior momento no transcorrer da doença, caracterizado como uma fase de medo, angústia e ansiedade. Referente ao tratamento, as mulheres apresentavam-se mais Queixosas Quanto aos efeitos colaterais causados por este, mostravam mais fragilidade e se sentiam manipuladas pela Quimioterapia. Já os homens não verbalizaram inquietude euanto ao tratamento.

Portanto, é notório Que os estereótipos criados pela sociedade acerca de gênero se traduzem no comportamento apresentado pelas pessoas Que adoecem de câncer, se fazendo necessário Que os profissionais Que cuidam deste tipo de paciente estejam atentos às diferenças de gênero e as respostas Que lhes são apresentadas de acordo com a etapa do processo de adoecer, a fim de adaptar uma comunicação terapêutica eficaz.

\section{REFERÊNCIAS}

1. Ministério da Saúde (BR). Instituto Nacional do Câncer. Estimativas 2010: Incidência de câncer no Brasil. Rio de Janeiro: INCA; 2010.

2. Coelho EAC. Gênero, saúde e enfermagem. Rev Bras Enferm 2005; 58(3): 345-8.

3. Farah FMS. Gênero e políticas públicas. Estudos Feministas 2004; 12(1): 47-7I.

4. De Vitta A, Neri AL, Padovani CR. Saúde percebida em homens e mulheres sedentários e ativos, adultos jovens e idosos. Salusvita 2006; 25 (1): 23-4.

5. Aquino, EML. Gênero e saúde: perfil e tendências da produção científica no Brasil. Rev Saúde Pública 2006; 40(esp).

6. Citeli MT. Fazendo diferenças: teorias sobre gênero, corpo e comportamento. Estudos Feministas 2001; 9(1): 131-45

7. Pinheiro RS, Viacava F, Travassos C, Brito AS. Gênero, morbidade, acesso e utilização de serviços de saúde no Brasil. Ciência Saúde Coletiva 2002; 7(4): 687-707.

8. Goldenberg M. Gênero e corpo na cultura brasileira. Psicol Clín 2005; 17(2): 65-80.

9. Leopardi MT, Beck CLC, Nietsche EA, Gonzales RMB. Metodologia da pesquisa na saúde. Santa Maria: Pallotti; 2001 .

10. Minayo MCS. O Desafio do Conhecimento - Pesquisa Qualitativa em saúde. $7^{\text {a }}$ ed. São Paulo: Hucitec; 2000.

11. Turato ER. Tratado de metodologia da pesquisa clínicoQualitativa: construção teórico-espistemológica, discussão comparada e aplicação nas áreas de saúde e humanas. Petróplois: Vozes; 2003.

12. Amaral CCG. Teoria e práxis dos enfoques de gênero. Fortaleza: NEGIF; 2004

13. Bardin L. Análise de Conteúdo. 4a Ed. Lisboa: Edições 70; 2010.
14. Ministério da Saúde (BR). Conselho Nacional de Saúde. Resolução 196/96. Inf Epidemiol SUS; 1996.

15. Kubler-Ross E. Sobre a morte e o morrer. $6^{\mathrm{a}}$ ed. São Paulo: Martins Fontes; 1994.

16. Sales CA, Molina MAS. O significado do câncer no cotidiano de mulheres em tratamento Quimioterápico. Rev Bras Enferm 2004; 57(6): 720-3.

17. Gianini, MMS. Câncer e gênero: enfrentamento da doença. Rev Psicol 2007. Disponível em: http://www.psicologia.com.pt/ artigos/textos/A0369.pdf

18. Silva VCE, Zago MMF. A revelação do diagnóstico de câncer para profissionais e pacientes. Rev Bras Enferm 2005; 58(4): 476-80.

19. Maciel MGS. A dor crônica no contexto dos cuidados paliativos. Rev Prática Hospitalar 2004; 6 (35).

20. Ferreira MLSM, Mamede MV. Representação do corpo na relação consigo mesma após mastectomia. Rev Latino-am Enfermagem 2003; II (3): 299-304.

21. Helman CG. Cultura, saúde e doença. $4^{\text {a }}$ ed. Porto Alegre: Artmed; 2003.

22. Paschoalick RC, Lacerda, MR, Centa, ML. Gênero masculino e saúde. Cogitare Enferm 2006; I I ( I): 80-6.

23. Braz M. A construção da subjetividade masculina e seu impacto sobre a saúde do homem: reflexão bioética sobre justiça distributiva. Ciência Saúde Coletiva 2005; 10 (1): 97-104.

24. Carvalho CSU. A necessária atenção à família do paciente oncológico. Rev Bras Cancerol 2008; 54 (1): 97-102.

25. Araujo MF. Diferença e igualdade nas relações de gênero: revisitando o debate. Psicol Clín 2005; 17 (2): 41-52.

26. Trindade WR, Ferreira MA. Grupo feminino de cuidado: estratégia de pesquisa-cuidado à mulher. Rev Bras Enferm 2009; 62(3): 374-80. 